Pacific Journal of Mathematics

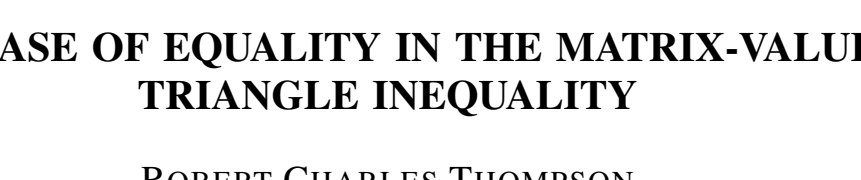




\section{THE CASE OF EQUALITY IN THE MATRIX-VALUED TRIANGLE INEQUALITY}

\section{ROBERT C. THOMPSON}

This paper presents an analysis of the case of equality in the matrix-valued triangle inequality. There is complete analogy with the case of equality in the usual scalar triangle inequality.

In order to describe our assertion more precisely, let $A$ and $B$ be $n$-square complex matrices, and by $|A|$ denote the positive semidefinite Hermitian matrix

$$
|A|=\left(A A^{*}\right)^{1 / 2},
$$

where $A^{*}$ is the adjoint of $A$. It has been speculated several times in the literature that this inequality should "naturally" hold:

$$
|A+B| \leqq|A|+|B|,
$$

where the inequality sign signifies that the right hand side minus the left hand side is positive semidefinite. This inequality is false, however, as easy $2 \times 2$ examples show. Nevertheless, there is a valid matrix valued triangle inequality. It was discovered in [1], and takes the form

$$
|A+B| \leqq U|A| U^{*}+V|B| V^{*}
$$

for appropriately chosen unitary matrices $U$ and $V$ (dependent upon $A$ and $B$ ). However, no analysis of a "case of equality" for (1) was given in [1], and the purpose of this note is to supply such an analysis. Specifically, we have:

THEOREM 1. The inequality sign in (1) must be equality if $A$ and $B$ have polar decompositions with a common unitary factor.

THEOREM 2. Suppose $A$ and $B$ are such that inequality (1) can hold only with the equality sign. Then $A$ and $B$ have polar factorizations with a common unitary factor.

Proof of Theorem 1. We have $A=W H$ and $B=W K$, where $W$ is unitary and $H, K$ are positive semidefinite Hermitian. From (1) we easily deduce that

$$
H+K \leqq U_{1} H U_{1}^{*}+V_{1} K V_{1}^{*},
$$


where $U_{1}, V_{1}$ are unitary. Thus the matrix $U_{1} H U_{1}^{*}+V_{1} K V_{1}^{*}-$ $(H+K)$ is positive semidefinite; but its trace is zero, so it can only be zero.

Proof of Theorem 2. We have to refer to the proof of the matrix triangle inequality in [1]. Let $C=A+B$. After multiplying $C, A$, and $B$ by a unitary factor to make $C$ positive semidefinite, and renaming the resulting matrices as $C, A, B$, again, the proof considers the expression

$$
C=\frac{1}{2}\left(A+A^{*}\right)+\frac{1}{2}\left(B+B^{*}\right),
$$

then uses $1 / 2\left(A+A^{*}\right) \leqq U|A| U^{*}$ for an appropriate unitary $U$, and a similar fact for $B$. The hypothesis in the theorem implies that we must have $1 / 2\left(A+A^{*}\right)=U|A| U^{*}$ (so that $1 / 2\left(A+A^{*}\right)$ is necessarily positive semidefinite). Squaring and taking traces, we get

$$
\operatorname{tr}\left(\frac{A+A^{*}}{2}\right)^{2}=\operatorname{tr} A A^{*}=\frac{\operatorname{tr} A A^{*}+\operatorname{tr} A^{*} A}{2} .
$$

Hence

$$
0=\operatorname{tr}\left(A-A^{*}\right)\left(A^{*}-A\right),
$$

so that $\left\|A-A^{*}\right\|^{2}=0$. Therefore $A$ is Hermitian. Since $1 / 2(A+$ $\left.A^{*}\right)$ is semidefinite, $A$ is semidefinite Hermitian. Similarly, so is $B$. That is to say: after multiplying the original $A, B, C$ by a unitary matrix to make $C$ semidefinite, $A$ and $B$ then also become semidefinite. This completes the proof.

\section{REFERENCE}

1. R. C. Thompson, Convex and concave functions of singular values of matrix sums, Pacific J. Math., 16 (1976), 285-290.

Received September 6, 1978. The preparation of this paper was supported in part by the U.S. Air Force, Grant 77-3166.

University of CALIFornia,

SANTA Barbara, CA 93106 


\section{PACIFIC JOURNAL OF MATHEMATICS}

\section{EDITORS}

DoNALD BABBITT (Managing Editor)

University of California

Los Angeles, California 90024

HUGo Rossi

University of Utah

Salt Lake City, UT 84112

C. C. MOORE and ANDREW OGG

University of California

Berkeley, CA 94720
J. DUGUNDJI

Department of Mathematics University of Southern Californı Los Angeles, California 90007

R. Finn and J. Milgram Stanford University Stanford, California 94305

\section{ASSOCIATE EDITORS}

E. F. BECKENBACH

B. H. Neumann
F. WOLF

K. YOSHIDA

\section{SUPPORTING INSTITUTIONS}

UNIVERSITY OF BRITISH COLUMBIA CALIFORNIA INSTITUTE OF TECHNOLOGY UNIVERSITY OF CALIFORNIA MONTANA STATE UNIVERSITY UNIVERSITY OF NEVADA, RENO NEW MEXICO STATE UNIVERSITY OREGON STATE UNIVERSITY UNIVERSITY OF OREGON
UNIVERSITY OF SOUTHERN CALIFORNIA STANFORD UNIVERSITY UNIVERSITY OF HAWAII UNIVERSITY OF TOKYO UNIVERSITY OF UTAH WASHINGTON STATE UNIVERSITY UNIVERSITY OF WASHINGTON 


\section{Pacific Journal of Mathematics}

Vol. 82, No. $1 \quad$ January, 1979

Werner Bäni, Subspaces of positive definite inner product spaces of countable dimension ...................................... 1

Marilyn Breen, The dimension of the kernel of a planar set..............

Kenneth Alfred Byrd, Right self-injective rings whose essential right ideals

are two-sided

Patrick Cousot and Radhia Cousot, Constructive versions of Tarski's fixed

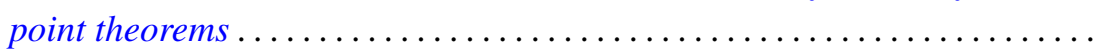

Ralph S. Freese, William A. Lampe and Walter Fuller Taylor, Congruence lattices of algebras of fixed similarity type. $I \ldots \ldots \ldots \ldots \ldots \ldots \ldots$

Cameron Gordon and Richard A. Litherland, On a theorem of Murasugi .....

Mauricio A. Gutiérrez, Concordance and homotopy. I. Fundamental

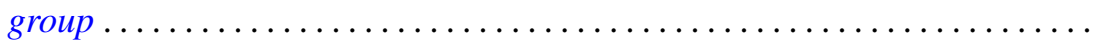

Richard I. Hartley, Metabelian representations of knot groups .............

Ted Hurley, Intersections of terms of polycentral series of free groups and free

Lie algebras ........................................

Roy Andrew Johnson, Some relationships between measures ............ 117

Oldřich Kowalski, On unitary automorphisms of solvable Lie algebras .......

Kee Yuen Lam, $K O$-equivalences and existence of nonsingular bilinear

maps...................................................

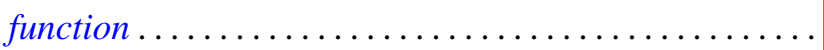

Robert A. Messer and Alden H. Wright, Embedding open 3-manifolds in compact 3-manifolds ............................

Gerald Ira Myerson, A combinatorial problem in finite fields. I . .

James Nelson, Jr. and Mohan S. Putcha, Word equations in a band of paths.

Baburao Govindrao Pachpatte and S. M. Singare, Discrete generalized Gronwall inequalities in three independent variables . .

William Lindall Paschke and Norberto Salinas, $C^{*}$-algebras associated with free products of groups ........................

Bruce Reznick, Banach spaces with polynomial norms ....

David Rusin, What is the probability that two elements of a finite group

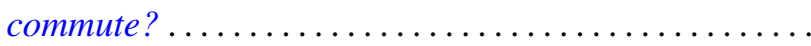

M. Shafii-Mousavi and Zbigniew Zielezny, On hypoelliptic differential operators of constant strength ...

Joseph Gail Stampfli, On selfadjoint derivation ranges .... . . .

Robert Charles Thompson, The case of equality in the matrix-valued triangle

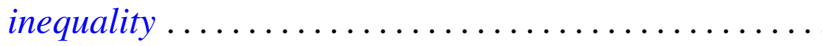

Marie Angela Vitulli, The obstruction of the formal moduli space in the negatively graded case. 